\title{
Determinants of Unmet Need for Family Planning among Women in Rural Kenya
}

\author{
Benard Nyauchi and Gilbert Omedi \\ nyauchib@yahoo.com; gilynes@yahoo.com
}

\begin{abstract}
This paper aimed at identifying factors that contribute to unmet need for family planning among women in rural Kenya. Logistic regression analysis was carried out on 2008/09 Kenya demographic and health survey women-file data that left out currently pregnant and amenorrheic women. Among the variables found to be significantly related to unmet need for spacing, limiting childbearing and total unmet need were: marital status, current age, level of education, number of living children, employment status, region, household wealth index and exposure to mass media communications. In order to reduce unmet need for family planning in rural areas of Kenya, region-specific programmatic family planning action should be adopted; the government should prioritize female education and economic empowerment to women in rural areas; agencies involved in family planning provision and communication in rural Kenya should offer suitable services that target specific age groups, and with a greater focus on married women.
\end{abstract}

Keywords: unmet need; fertility; contraception; unintended pregnancy; rural residence.

\section{Résumé}

Ce document vise à identifier les facteurs qui contribuent à des besoins non satisfaits de planification familiale chez les femmes dans le Kenya rural. Analyse de régression logistique a été réalisée sur 2008/09 Kenya enquête démographique et de santé des femmes données-fichier qui a laissé de côté les femmes enceintes et aménorrhée. Parmi les variables trouvées liées de façon significative à des besoins non satisfaits pour l'espacement, limitant procréer et les besoins non satisfaits totale étaient: l'état matrimonial, l'âge actuel, le niveau d'éducation, le nombre d'enfants vivants, statut d'emploi, la région, l'indice de richesse des ménages et l'exposition aux médias de masse communications. Afin de réduire les besoins non satisfaits de planification familiale dans les zones rurales du Kenya, de l'action de planification familiale programmatique spécifique à la région devrait être adopté; le gouvernement devrait prioriser l'éducation des femmes et l'autonomisation économique des femmes dans les zones rurales; organismes impliqués dans la prestation de planification familiale et de la communication dans le Kenya rural devraient offrir des services adaptés qui ciblent des groupes d'âge spécifiques, et avec une plus grande focalisation sur les femmes mariées.

Mots clé: besoins non satisfaits; la fertilité; la contraception; les grossesses non désirées; la résidence 


\section{Introduction}

Rates of unmet need for family planning remain highest among developing countries where one in every four women in their reproductive age remain exposed to unintended pregnancies or are unable to postpone childbirth (Casterline and Sinding, 200I; Sedgh, et al. 2008). Being part of the developing world in question, Kenya also experiences high levels of unmet need for contraception. According to KNBS and ICF Macro (2010), the country still needs a lot of services in this area with 26 percent of currently married women in dire need of family planning. Moreover, there are variations in contraceptive use based on place of residence in that urban settings experience a higher prevalence than rural areas. These variations have seen a higher unmet need for contraception among married women in rural areas (27 percent) against their counterparts in urban areas (20 percent). While the desired average number of children in Kenya is estimated to be about 4.0, which is way much lower than the total fertility of 4.6, actual desired family size is bigger among women in rural areas (at 4.0 children) against urban women whose desired average number of children is 3.I. Total fertility rate in rural areas remains higher at 5.2 against that of urban women which is at a low of 2.9. That prevalence of contraception remains at 46 percent, it is arguable that women's inability to access contraceptive services is a contributory factor to this situation. Because of lower contraceptive prevalence (of 43 percent) in rural Kenya than in urban areas (at 53 percent) (KNBS and ICF Macro, 20I0), there is need to present women in rural areas with adequate family planning services. The implication here is that total fertility rate in rural areas is about 30 percent higher than it would be if unintended pregnancies were prevented.

This gap between desired fertility and actual fertility suggests the extent of mistimed and unintended pregnancies in rural areas of the country. There is therefore need to document this gap, in terms of actual and potential contraception, so that the assessment of determinants of unmet need for family planning that is based on urban-rural residence becomes important for purposes of programming family planning in Kenya and for informing the population policy making process. As such, the findings of this study would be used to inform policy makers and organisations implementing family planning and reproductive health programmes in Kenya for planning programme strategies, projecting budgets and resources, as well as assessing programme outcomes (Dixon-Mueller and Germain, 1992). Unmet need for family planning also has a relationship with maternal health and child health, so that, if unintended or mistimed pregnancies are reduced by ensuring increased knowledge and use of family planning services, the current high maternal mortality ratio and child and infant mortality rates in rural areas will as well reduce. Improved knowledge and use of contraception in rural Kenya will also effectively reduce the high fertility in rural areas, and this will relieve the country from the pressure that rapid population growth places on economic, social and natural resources.

Also worth noting, several studies (such as Wangila, 200I; Oluteyo, 2005; Omwago and Khasakhala, 2006; Ojakaa, 2008) on unmet need for family planning have mainly focused on currently married women or those in unions, therefore, left out single, divorced, separated and widowed women. However, it should be noted that some of these women are sexually active, and they too could experience unmet need for family planning but are often excluded from measurements that focus on unmet need. Their exclusion in such measurements means an underestimation of levels of unmet need for family planning (Ross and Winfrey, 2002). As a result, the extent of unmet need for women with these characteristics is barely known, therefore, the interest to include such women in measurement using a suitable data. Besides, factors underlying high levels of unmet need for family planning among women in rural areas are not well understood. Moreover, none of the studies have considered women's migration status as a factor that is likely to affect unmet need for contraception. Thus, this study was very appropriate in filling knowledge gap surrounding the factors underlying unmet need for contraception in Kenya's rural areas. On this basis, this study sought to uncover factors that contribute to high rates of unmet need of family planning among women in Kenya's rural areas with a focus on the importance of these factors in determining child spacing decisions as well as choices for birth limitation.

\section{Literature Review}

\section{Empirical Literature}

As Klijzing (2000) asserts, however much limited evidence is available, some level of unmet need for contraception is likely to exist in every country, regardless of their development levels. Thus, 
developed or developing, every country experiences some degree of unmet need even if the country has a wide use of family planning. Various studies have been conducted in both developing and developed countries to explain factors that influence uptake of family planning and factors associated with women's unmet need for family planning. However, little attention has been paid to research on unmet need among women in rural Kenya. Below is a discussion of some of the studies.

In their attempt to understand the influences on the desire for more children and current contraceptive practice, Withers, et al. (2010) found that younger women had fewer living children, had given birth in the past one year, had regular access to health services and were more likely to desire to add children. In this study, it was established that being older, having fewer living children, lack of regular access to health care services, having had a delivery in the last one year and having the desire for more children are associated with lower likelihood of contraceptive use. It was also established that women with regular access to health care are more likely to desire more children, a point pinned on the fact that these women are more confident in their ability to have successful birth outcomes. The study findings identify older women and postpartum women as key target groups for family planning, even though these women may not be able to see themselves to be at risk of unintended pregnancies. The researchers concluded that meeting unmet need for family planning for these groups could help them meet their fertility goals, as well as reduce maternal morbidity and mortality.

As he was examining the trends and determinants of unmet need for family planning methods in Kenya, Ojakaa (2008) found that total unmet need decreases with a women's age, level of education, household wealth, exposure to family planning messages, and employment. Other significant findings of the study are that total unmet need is higher among women with larger number of living children and among those who have primary level of education. Ojakaa (2008) also reports that working women are more likely to report methodrelated reasons for not using family planning methods and are less likely to report opposition to family planning than women who do not work. His regression analysis reveals that several variables such as women's age, number of living children, level of education, household wealth, current work status, exposure to media messages about family planning, discussion with the partner about family planning and contact with health services are significantly related to total unmet need.

While studying unmet need for family planning in Kenya, Karanja (1997) established that there was a positive association between contraceptive prevalence and lack of information on family planning, and that urban areas recorded lower rates of unmet need for family planning compared to rural areas. Moreover, given that contraception is used either for child spacing or for limiting births, the study found out that higher unmet need exists in rural areas for child spacing and birth limiting (22.8 percent and 19.4 percent respectively). On the other hand, there were lower rates of unmet need in urban areas (I7.7 percent and I5.4 percent) for spacing and limiting child births, respectively. The study also established that older women tend to have unmet need for child spacing whereas a woman with a bigger family size would necessarily seek for family planning to limit child bearing, and that there is no favourable association between unmet need for family planning and level of education.

\section{Data and Method of Analysis}

This study utilised data from 2008/09 Kenya Demographic and Health Survey which involved a nationally representative sample of 8,444 women in their reproductive ages. From this, a sample of 5,829 women from rural areas was selected for analysis. However, currently pregnant and amenorrhea women were excluded from the analysis since they are not currently exposed to the risk of becoming pregnant regardless of them having previously planned or not planned their current pregnancies (Westoff and Pebley, 198I). Moreover, inclusion of these women in this study would overestimate the level of unmet need in Kenya's rural areas (Bongaarts, 1991). According to Nortman (1982), inclusion of pregnant women in such a study would be problematic because pregnant women are less likely to accept that their pregnancies are unintended or mistimed. Westoff and Bankole (2000) have also suggested that pregnant and amenorrhea women should be excluded from the measurement of unmet need, thus on this basis, these two groups were excluded in this study.

This study employed multivariate logistic regression, presented in the form of log of odds to a set of variables. Nine independent variables were run against the three aspects of unmet need, and were grouped according to their broad categories: Economic Factors: employment status and household 
wealth; Social Factors: level of education and region of residence; Demographic Factors: age, marital status, number of living children and migration status; and Socio-familial and Individual Factors: exposure to mass communication.

A woman's current employment status represents her most recent involvement in any form of employment and was categorised as 'Employed' for women who earn salary or wages, and 'Not employed' for those not involved in any form of gainful employment. Household wealth index is a composite measure of households' cumulative living standards that places individual households on a continuous scale of relative wealth. In this study, wealth index was re-coded into three: 'Low' for the lowest quintile, 'Average' for the second and middle quintiles and 'High' for the fourth and highest quintiles. Level of education represents the highest level of formal schooling attained by the woman, and was categorised as 'No education', 'Primary' and 'Secondary and above'. Region of residence has been used to refer to the province where the woman resides: Central, Nairobi, Coast, Eastern, Nyanza, Rift Valley, Western and North Eastern. The ages of respondents were categorised as '15-24 years', '2534 years' and ' 35 or more years'. In relation to marital status, respondents were either 'Ever married' to include those currently married, living together, divorced, separated or widowed; and 'Never married'. In terms of number of children living, women were classified as having no children, between one and two children, between three and four children or having five or more children. Respondents were also categorised as ever migrated or never migrated from urban areas over the last five years. Exposure to mass media was categorised as 'Ever listened' for those who have accessed mass media at any point in their lives or 'Never listened'.

The choice for these nine independent variables was founded on the existing literature that these variables were significantly associated with unmet need for family planning in rural areas. Three models were derived based on the nature of unmet need, the dependent variable: Model I - unmet need for limiting child bearing; Model II - unmet need for spacing of child births; and Model III - overall unmet need for family planning. For each model, all the nine independent variables were run. However, only independent variables which had significant association with outcome variables were selected and displayed in each table.

\section{Results}

\section{Model I: Determinants of Unmet Need to Limit Childbearing}

Results in Table I show that household wealth, educational levels, region of residence, marital status and number of living children determine level of unmet need for family planning to limit child bearing in rural areas. Women from households with greater wealth indices are more likely to experience lower levels of unmet need. As wealth levels increase, the level of unmet need for limiting child bearing reduces. Ojakaa (2008) associates this to the fact that women from wealthy households are capable of purchasing family planning services, thus able to use contraception to limit childbearing.

Several studies have found out that there is no clear association between a woman's educational level and her demand for family planning (Ojakaa 2008; Wangila 200I; Westoff, 2006). Findings of this study reveal that women who attained education up to primary level are most likely to experience unmet need to limit child bearing compared to those who have either not attempted school or have attained some secondary education.

Compared to their counterparts from Central Province, women from Eastern and North Eastern provinces are less likely to have unmet need for limiting child births. This may be associated with the fact that women in these areas are not interested in limiting their child bearing and therefore have not seen the need to seek for contraception. Women in rural areas of these provinces have exhibited greater number of living children, evidence that contraception is not fully embraced by the women.

Marital status is also associated level of unmet need. Women who have ever been married are more likely to experience unmet need for family planning to limit child bearing. A woman who has ever been married is about 4 times more likely to have unmet need for family planning to limit child bearing than an unmarried one $(p<0.05)$. 
Table I: Factors that Determine Unmet Need to Limit Childbearing

\begin{tabular}{|c|c|c|c|c|c|}
\hline Variable & Log of Odds & S.E. & d.f. & $p$-value & Odds Ratio \\
\hline Household wealth index & & & 2 & $<0.01$ & \\
\hline Low & 0 & & & & 1 \\
\hline Average & -0.378 & 0.154 & & & $0.685^{* *}$ \\
\hline High & -0.06 & 0.293 & & & 0.941 \\
\hline Highest level of education & & & 2 & $<0.01$ & \\
\hline No education & 0 & & & & 1 \\
\hline Primary & 0.357 & 0.197 & & & $1.429^{\star * \star}$ \\
\hline Secondary and above & -0.132 & 0.249 & & & 0.876 \\
\hline Region of residence & & & 6 & $<0.01$ & \\
\hline Central & 0 & & & & 1 \\
\hline Coast & -0.382 & 0.392 & & & 0.682 \\
\hline Eastern & -0.883 & 0.386 & & & $0.413^{* *}$ \\
\hline Nyanza & -0.523 & 0.467 & & & 0.593 \\
\hline Rift valley & -0.015 & 0.357 & & & 0.985 \\
\hline Western & -0.087 & 0.452 & & & 0.916 \\
\hline North Eastern & -2.585 & 1.277 & & & $0.075^{* *}$ \\
\hline Marital status & & & 1 & $<0.01$ & \\
\hline Never married & 0 & & & & 1 \\
\hline Ever married & 1.432 & 0.492 & & & $4.187^{* *}$ \\
\hline Number of living children & & & 3 & $<0.01$ & \\
\hline 1-2 children & 3.261 & 1.063 & & & $26.087^{* *}$ \\
\hline 3-4 children & 3.846 & 1.075 & & & $46.789^{*}$ \\
\hline $5+$ children & 4.571 & 1.079 & & & $96.596^{*}$ \\
\hline Constant & -7.68 & 1.054 & 1 & $<0.01$ & $0.000^{\star}$ \\
\hline
\end{tabular}

${ }^{*} p$-value $<0.01$; **p-value $<0.05$; ***p-value $<0.1$

Source: Primary Analysis of 2008/09 KDHS

Exposure of these women to frequent coital activity may be a reason behind high levels of unmet need as witnessed among them. Such women are therefore more likely to lack opportunity to control their child bearing in terms of numbers. As the number of living children a woman has increases, her level of unmet need for family planning is likely to rise. The findings in Table I reveal that women with five or more children are the most affected. The reason why women in rural areas may find themselves having many child births is because they are unable to access and utilise family planning services.

\section{Model II: Determinants of Unmet Need to Space Childbearing}

Results shown in Table 2 reveal that a rural woman's employment status still remains an important determinant of her level of unmet need for spacing childbirths. With regard to this, it is clear that women who are currently employed are less likely to experience unmet need to space compared to women who are not employed. Casterline et al. (1997) argue that women who are employed have the capacity to make decision and to purchase contraceptives to space their births. Moreover, it is arguable that currently employed women would need adequate time to concentrate more on their employment-related activities than family matters, as such would opt to space their births (Becker 1991). Coupled with the difficulty a woman faces in acquiring maternity leave, many women would not want to frequently seek for maternity leaves from their employers, thus would want to have wider spaces between their births.

A rural woman's level of education can predict her level of unmet need for contraception to space. This is because the lower the level of education, the greater the chances that such a woman would have unmet need for spacing. From Table 2, it is evident that women with primary education are most likely to have unmet need for spacing. However, the level of unmet need reduces with rise in educational level, such that individuals with post-secondary education are least likely to experience unmet need to space childbirths. It is arguable that education imparts knowledge on the importance of using contraception to space childbirths. Moreover, education presents a woman with opportunity to interact with other women from diverse cultural and geographical bounds, from which they are able to acquire new information and skills including use of family planning to space births. 
Table 2: Factors that Determine Unmet Need for Family Planning to Space Child Births

\begin{tabular}{|c|c|c|c|c|c|}
\hline Variable & Log of Odds & S.E. & d.f. & $p$-value & Odds Ratio \\
\hline Current employment status & & & 1 & $<0.01$ & \\
\hline Employed & 0 & & & & 1 \\
\hline Not employed & 0.348 & 0.144 & & & $1.417^{\star *}$ \\
\hline Highest level of education & & & 2 & $<0.01$ & \\
\hline No education & 0 & & & & 1 \\
\hline Primary & -0.579 & 0.219 & & & $0.560^{* *}$ \\
\hline Secondary and above & -0.988 & 0.284 & & & $0.372^{*}$ \\
\hline Region of residence & & & 6 & $<0.01$ & \\
\hline Central & 0 & & & & 1 \\
\hline Coast & 1.073 & 0.514 & & & $2.924^{\star \star}$ \\
\hline Eastern & 0.322 & 0.523 & & & 1.38 \\
\hline Nyanza & 1.267 & 0.6 & & & $3.550^{* *}$ \\
\hline Rift valley & 0.836 & 0.501 & & & $2.306^{\star * *}$ \\
\hline Age & & & 2 & $<0.01$ & \\
\hline $15-24$ years & 0 & & & & 1 \\
\hline $25-34$ years & -0.732 & 0.174 & & & $0.481^{*}$ \\
\hline $35+$ years & -2.361 & 0.247 & & & $0.094^{*}$ \\
\hline Marital status & & & 1 & $<0.01$ & \\
\hline Never married & 0 & & & & 1 \\
\hline Ever married & 1.547 & 0.296 & & & $4.699^{*}$ \\
\hline Number of living children & & & 3 & $<0.01$ & \\
\hline 0 & 0 & & & & 1 \\
\hline $1-2$ children & 1.536 & 0.289 & & & $4.648^{*}$ \\
\hline 3-4 children & 1.389 & 0.322 & & & $4.011^{*}$ \\
\hline $5+$ children & 1.275 & 0.356 & & & $3.579^{*}$ \\
\hline Exposure to mass media & & & 1 & $<0.01$ & \\
\hline Never listened & 0 & & & & 1 \\
\hline Ever listened & -0.543 & 0.175 & & & $0.581^{*}$ \\
\hline Constant & -4.493 & 0.462 & 1 & $<0.01$ & $0.011^{*}$ \\
\hline
\end{tabular}

*p-value $<0.01 ; * *$-value $<0.05 ; * * *$-value $<0.1$

Source: Primary Analysis of 2008/09 KDHS

Table 2 further shows that women in rural areas of Coast, Nyanza and Rift Valley provinces have high likelihoods of experiencing unmet need for spacing. A rural woman in Coast Province for instance, is about three times more likely to experience unmet need for spacing than a rural woman in Central Province. Similarly, women in Nyanza and Rift Valley provinces are 3.55 and 2.31 times, respectively, more likely to have unmet need for spacing their births compared to women in Central province of Kenya.

As age increases, a woman from rural area's propensity of having unmet need for family planning to space child bearing decreases. This trend is so consistent that younger women are bound to experience higher risk of unmet need for contraception to space births. As Wangila (200I) points out, as women grow older by age, they tend to achieve their desired family sizes. Moreover, older women tend to have a reduced coital frequency, and therefore may not need contraception to space their births (Robey, et al. 1996; Casterline, et al. 1997).

Marital status of a woman living in a rural setup is another pointer of likelihood of experiencing unmet need for family planning to space births. Results in Table 2 show that married women in rural areas are almost 5 times more likely to have unmet need to space children than their unmarried counterparts. As such, women who have ever been married are more likely to experience unmet need mainly because of their exposure to frequent coital activity.

There is a highly positive association between unmet need for family planning to space births and the number of living children a rural woman currently has. This is because higher number of children is usually accompanied by an increased demand for family planning (Wangila, 200I). As such, women in rural areas with more children are more likely to have greater unmet need to space births than those with fewer living children. As the number of children a woman currently has increases, the level of unmet need to space births increases because as more children survive, women tend to 
achieve desired family size, thus will seek to further limit child bearing.

There is a distinct association between exposure to mass media, measured by the proportion who have ever listened to radio and unmet need for contraception to space childbirths. Women who have ever listened to radio communications are less likely to have unmet need for spacing childbirths. This could be because mass media has often been used to influence fertility decisions among women, as well as to inform and motivate women to access contraception (Westoff and Rodriguez, 1995).

Model III: Determinants of Overall Unmet Need for Family Planning

Results in Table 3 show that a rural woman's employment status still remains an important variable in determining her level of unmet need for family planning. As such, it is clear that women who are currently employed are less likely to experience unmet need for family planning as compared to those women who are not employed. As far as Casterline et al. (1997) are concerned, women who are employed have the capacity to make their own decisions to purchase contraceptives.

Similarly, household wealth is another determinant of level unmet need among rural women in Kenya. This is because women from poorer households tend to have significantly higher levels of unmet need than those from wealthier households. Just like the findings in Table I, wealthier households have significantly lesser total unmet need for family planning. Moreover, it is evident that households with lower wealth indices are more likely to experience total unmet need for family planning. This conforms to the argument posed by Ojakaa (2008) that women from wealthier households are more likely to adopt family planning because they are more able to afford contraception.

A rural woman's level of education is inversely associated with level of unmet need for family planning. As such, the higher the level of education, the lower the likelihood of having unmet need for family planning. However, women who have attained primary education tend to have a significantly higher likelihood of experiencing unmet need for family planning than those who did not attempt any level of education. This is as well expected and Robey et al. (1996) are convinced that there seems to be no consistent relationship between level of education and level of unmet need for family planning. 
Table 3: Factors that Determine Overall Unmet Need for Family Planning

\begin{tabular}{|c|c|c|c|c|c|}
\hline Variable & Log of Odds & S.E. & d.f & $p$-value & Odds Ratio \\
\hline Current employment status & & & 1 & $<0.01$ & \\
\hline Employed & 0 & & & & 1 \\
\hline Not employed & 0.2 & 0.102 & & & $1.221^{* *}$ \\
\hline Household wealth index & & & 2 & $<0.01$ & \\
\hline Low & 0 & & & & 1 \\
\hline Average & -0.218 & 0.12 & & & $0.804^{* * *}$ \\
\hline High & -0.152 & 0.237 & & & 0.859 \\
\hline Highest level of education & & & 2 & $<0.01$ & \\
\hline No education & 0 & & & & 1 \\
\hline Primary & -0.035 & 0.153 & & & 0.966 \\
\hline Secondary and above & -0.531 & 0.195 & & & $0.588^{* *}$ \\
\hline Age & & & 2 & $<0.01$ & \\
\hline $15-24$ years & 0 & & & & 1 \\
\hline 25-34 years & -0.671 & 0.147 & & & $0.511^{*}$ \\
\hline $35+$ years & -1.07 & 0.164 & & & $0.343^{*}$ \\
\hline Marital status & & & 1 & $<0.01$ & \\
\hline Never married & 0 & & & & 1 \\
\hline Ever married & 1.678 & 0.256 & & & $5.354^{*}$ \\
\hline Number of living children & & & 3 & $<0.01$ & \\
\hline 0 & 0 & & & & 1 \\
\hline 1-2 children & 1.582 & 0.263 & & & $4.867^{*}$ \\
\hline 3-4 children & 1.821 & 0.285 & & & $6.180^{*}$ \\
\hline $5+$ children & 2.298 & 0.295 & & & $9.955^{*}$ \\
\hline Exposure to mass media & & & 1 & $<0.01$ & \\
\hline Never listened & 0 & & & & 1 \\
\hline Ever listened & -0.267 & 0.127 & & & $0.765^{\star *}$ \\
\hline Constant & -4.179 & 0.316 & 1 & $<0.01$ & $0.015^{\star}$ \\
\hline
\end{tabular}

As age increases, a rural woman's propensity of having unmet need for family planning decreases. There is consistency of this trend in relation to total unmet need for family planning. Thus, younger women are most likely to experience higher risk of overall unmet need for contraception. This is because as a woman lives longer, she is more likely to continue giving birth to more children and therefore would achieve desired family size (Wangila, 200I). As well, there is a tendency among older women to have reduced frequency of involvement in coital activity, therefore may not frequently need contraception to control their fertility (Robey, et al. 1996; Casterline, et al. 1997).

A woman's marital status is a significant determinant of unmet need for family planning. Basing on the results of these analyses, an ever married woman in rural Kenya is 5.35 times more likely to have unmet need than one who has never been married. This disparity could be because most of rural women who have never been married are not as frequently engaged in coital practice as those who have ever been married, and it is also likely that a number of these unmarried women are still attending school. This could be the main reason as to why a lot of studies on unmet need for family planning have exclusively focused on married women rather than the total women population.

The greater the number of living children a woman has the higher her likelihood of experiencing unmet need for family planning. However, conspicuous from the results is the effect of number of living children on unmet need for limiting births. This positive association gives an impression that the more children survive, the more women tend to attain their desired family size, and thus the desire to limit further childbearing (Wangila 200I; Lwanga 1999). Moreover, as more children survive, women 
feel the security and then desire to limit childbearing by adopting contraception. Hence, women with more children are more likely to exhibit greater levels of unmet need.

The more frequent a woman listens to mass media communications the lesser her chances of experiencing unmet need for family planning. According to Lasee and Becker (1997) in their analysis of 1989 Kenya Demographic and Health Survey data, there exists a strong association between women reporting that they have heard messages about family planning from mass media and contraceptive prevalence among these women. In this study, women from rural Kenya who listen to radio are less likely to have unmet need for spacing births and total unmet need for family planning.

\section{Conclusion and Recommendations}

This study aimed at establishing the determinants of unmet need for family planning among women in Kenya's rural areas. Women in rural areas, according to the 2008/09 KDHS are exposed to greater chances of experiencing unmet need for family planning (KNBS \& ICF Macro, 20I0), and therefore, a proper understanding of factors that determine this is important. Analytical results show that among women in rural Kenya, household wealth status, level of education of the respondent, region of residence, number of living children, and marital status are significantly associated with unmet need for limiting childbearing, while current employment status, level of education of the respondent, region of residence, current age, marital status, number of living children and exposure to mass media are significantly related to unmet need to space childbirths. Total unmet need is influenced by a woman's current employment status, household wealth index, level of education, current age, marital status, number of living children, and exposure to mass media.

The study carries a number of policy implications: family planning programmatic activities in rural areas of Kenya should be both region-and age group-specific and give a lot of weight to married women. The government should encourage active female involvement in education, promote girl child education in rural areas and reward women who have achieved education excellence in respective grades so as to encourage women's involvement in education to higher levels. Also, programmes geared towards wealth creation such as women's involvement in micro-finance operations, participation in employment opportunities, involvement in cash crop agricultural production, and the economic empowerment among rural women should be encouraged to enable women acquire access to contraception thus reduce the high levels of unmet need for family planning in rural areas. Future studies should attempt to assess the factors that determine unmet need for family planning among women in urban areas of Kenya. The significance of such studies will inform the place of residence-specific programmatic actions. Moreover, such studies will provide adequate information to offer solution to the currently increasing fertility among women in poor urban settlements and slums.

\section{Acknowledgement}

We wish to acknowledge Prof. Otieno T. A. Agwanda of University of Nairobi, Kenya and Dr. Francis Obare of Population Council, Kenya for their contribution and valuable insights towards the development of this document.

\section{Authors' Contribution}

Benard Nyauchi identified the problem, scope and limitations, conducted literature review and theoretical framework and participated in the discussion, conclusion and recommendations.

Gilbert Omedi conducted the primary analysis and participated in the discussion, conclusion and recommendations as well.

The two authors jointly edited the document to fit the requirements of the UAPS Editorial Team.

\section{References}

Becker, G.S. 1991. A Treatise on the Family. Cambridge, Mass.: Harvard University Press.

Bongaarts, J.M. 1991. "The KAP-Gap and the Unmet Need for Contraception." Population and Development Review, I7(2): 293-313.

Casterline, J.B. and Sinding, S.W. 200I. "Unmet Need for Family Planning in Developing Countries and Implications for Population Policy." Population and Development Review, 2I(I):69I-723.

Casterline, J.B., Perez, A.E. and Anne, B.E. 1997. "Factors Underlying Unmet Need for Family Planning in the Philippines." Studies in Family Planning, 28(3): I73-191.

Dixon-Mueller, R. and Germain, A. 1992. "Stalking the Elusive Unmet Need for Family Planning." Studies in Family Planning, 23(5): 330-335.

Karanja, S.M. 1997. Unmet Need for Contraception and their Demographic Significance in Kenya. Unpublished M.A. Thesis, PSRI: University of Nairobi. 
Kenya National Bureau of Statistics and ICF Macro. 2010. 2008/09 Kenya Demographic and Health Survey. Calverton, Maryland: KNBS and ICF Macro.

Klijzing, E. 2000. “Are There Unmet Family Planning Needs in Europe?" Family Planning Perspectives, 32(2)74-8I.

Lasee, A. and Becker, S. 1997. "Husband-Wife Communication about Family Planning and Contraceptive Use in Kenya." International Family Planning Perspectives, 23(I): 15-20 \& 33.

Lwanga, K.C. 1999. Determinants of Unmet Need for Contraception in Zambia. Unpublished M.A. Thesis, PSRI: University of Nairobi.

Nortman, D.L. 1982. "Measuring Unmet Need for Contraception to Space and Limit Births." International Family Planning Perspectives, 8(4): 125-134.

Ojakaa, D. 2008. "Trends and Determinants of Unmet Need for Family Planning in Kenya." DHS Working Papers No. 56. Calverton, MD: Macro International, Inc.

Oluteyo, M.D. 2005. Determinants of Unmet Need for Contraception among Women in Kenya. Unpublished M.A. Thesis, PSRI: University of Nairobi.

Omwago, M.O. and Khasakhala, A.A. 2006. "Factors Influencing Couples' Unmet Need for Contraception in Kenya." African Population Studies, 2 I (2): 75-94.

Robey, B., Ross, J. and Bushan, I. 1996. "Meeting Unmet Need: New Strategies." Population Reports, 43:I-35.

Ross, J.A. and Winfrey, W.L. 2002. "Unmet Need for Contraception in the Developing World and the Former Soviet Union: An Updated Estimate." International Family Planning Perspectives, 28(3): | $38-\mid 43$.
Sedgh, G., Bankole, A. and Hussain, R. 2008. Reasons behind the Unmet Need for Contraception in Developing Countries. Paper Presented at the 2008 PAA Annual General Meeting, April 17-19 2008, New Orleans, USA.

Wangila, S.W. 200I. Factors Underlying Unmet Need for Contraception in Kenya. Unpublished M.A. Thesis, PSRI: University of Nairobi.

Westoff, C.F. 2006. "New Estimates of Unmet Need and Demand for Family Planning." DHS Comparative Report no. 14. Calverton, Maryland, USA: Macro International Inc.

Westoff, C.F. and Bankole, A. 2000. "Trends in the Demand for Limitation in Developing Countries." International Family Planning Perspectives, 26(2): 56-62 \& 97.

Westoff, C.F. and Pebley, A. 198I. "Alternative Measures of Unmet Need for Family Planning in Developing Countries." International Family Planning Perspectives, 7(4): 126- 136.

Westoff, C.F. and Rodriguez, G. 1995. "The Mass Media and Family Planning in Kenya." International Family Planning Perspectives, 2I(I):26-3I \& 36.

Withers, M., Kano, M. and Pinatih, G.N. 2010. "Desire for More Children, Contraceptive Use and Unmet Need for Family Planning in a Remote Area of Bali, Indonesia." Journal of Biosocial Science, 42: 549-562. 